DOI: $10.17805 /$ zpu.2016.2.5

\title{
Этническая идентичность в контексте теории потребностей *
}

\author{
О. В. ДОЛЖЕНКОВА, Ю. В. ПОПКОВ \\ (ИНСТИТУТ ФИЛОСОФИИ И ПРАВА СИБИРСКОГО ОТДЕЛЕНИЯ РАН, \\ Г. НОВОСИБИРСК)
}

Этническая идентичность рассматривается как явление, обусловленное наличием устойчивых потребностей в ней. Цель статьи состоит в том, чтобы на основе обобщения широкого корпуса литературных источников выявить те потребности, с которыми связана этническая идентичность. На основе проведенного анализа показано, что этническая идентичность является формой проявления аффилиативной потребности, и в этом качестве она взаимосвязана как со специфическими человеческими потребностями, в частности с потребностью в нормативном регулировании, так и с базовыми витальными потребностями в виде потребности в самосохранении.

Отталкиваясь от специфики этнической идентичности, авторы прослеживают ее связь с социально-экономической сферой, являющейся основой обеспечения потребности в самосохранении.

В частности, изменение этнической идентичности может рассматриваться как стратегия выживания через обеспечение полноценного участия в экономической жизни общества в условиях, когда старые нормы поведения перестают соответствовать требованиям измененной социальной среды. Подобная стратегия может реализовываться и посредством сохранения этнической идентичности, если имеется экономическая ниша, обеспечивающая полноценную адаптацию обладателей данной идентичности к социальным условиям. Столь тесная связь этнической идентичности с потребностью в самосохранении, реализующейся посредством экономических потребностей, объясняется тем, что изначально этническая общность обеспечивала полный цикл жизнедеятельности и удовлетворение всего комплекса необходимых потребностей. Этот факт был следствием присущего традиционному обществу синкретизма всех сторон жизни человека.

Разделение моментов социальной и личностной ориентации в исследовании этнической идентичности отражает расщепление этой целостности жизнеобеспечения. Так, смена этнической идентичности в контексте личностной ориентации связана с обособлением потребности, обеспечивающей психологическую устойчивость существования индивида. Другим следствием расщепления целостности жизнеобеспечения становится рост опосредованности процесса реализации основных потребностей. Потребность в самосохранении начинает осуществляться через инструментальное использование этнической идентичности для удовлетворения экономических потребностей, и особое значение приобретает изучение нормативно-ценностного компонента этнической идентичности. Первоначально этническая общность обеспечивала весь цикл жизнедеятельности индивида, поэтому этническая идентичность непосредственно связана с нормативным регулированием. Однако в ходе расщепления исходной целостности материальной и духовной сфер ценности перестают быть напрямую связанными с потребностью в самосохранении и также могут приобретать инструментальное значение.

Ключевые слова: этническая идентичность; этничность; потребности; потребность в самосохранении

* Работа выполнена по проекту «Влияние этнокультурного неотрадиционализма на формирование общенациональной и этнической идентичности»в рамках Комплексной программы Сибирского отделения Российской академии наук № II.2.

The article was written as part of the project "Ethnocultural neo-traditionalism and its influence on the rise of civil and ethnic identity", No.II.2, Comprehensive Program, Siberian Branch, Russian Academy of Sciences. 


\section{ВВЕАЕНИЕ}

Ј сследование этнической идентичности принято связывать с двумя основными подходами: онтологическим, рассматривающим этничность как нечто фундаментально присущее человеку, и ситуативным, в котором этническая идентичность рассматривается как конструкция, служащая удовлетворению текущих интересов. Однако если абстрагироваться от противопоставления этих подходов и взять за основу только факт существования этнической идентичности в ряду других общественных явлений, то возникает вопрос о функциональных требованиях социальной системы, реализации которых соответствует этническая идентичность. Понятие функциональных требований соотносится с понятием потребностей (Мертон, 1994: 414-415), в связи с чем этническую идентичность можно рассматривать с точки зрения тех потребностей, к реализации которых она имеет отношение.

\section{ПОНЯТИЕ ПОТРЕБНОСТИ И ИХ КААССИФИКАЦИЯ}

Чаще всего потребность определяется через понятие «нужды», но ее научное определение предполагает также рассмотрение отношения противоречия между наличным и необходимым, которое является движущей силой поведения (Каверин, 1998: 26, 31; Каган, Маргулис, Хмелев, 1976: 6, 10).

Чтобы определить место этнической идентичности в системе потребностей, важно отталкиваться от двух оснований. Первое состоит в определении взаимосвязей этнической идентичности с потребностями через их классификацию, второе - в выявлении специфики самой этой идентичности.

Известно, что существует множество классификаций потребностей. С точки зрения задач настоящей статьи заслуживают внимания две классификации российских исследователей - П. В. Симонова и С. Б. Каверина. П. В. Симонов выделяет биологические (витальные), социальные и идеальные потребности, при этом отмечая, что у человека нет чисто биологических потребностей, так как они опосредованы социальной средой, и в то же время социальное в человеке имеет предысторию своего существования на «дочеловеческом этапе» (Симонов, 1987: 44-45). К биологическим, призванным обеспечить индивидуальное и видовое существование человека, он относит потребности в пище, сне и т. А., к собственно социальным - потребность принадлежать к социальной общности и потребность следовать нормам, без которых невозможно существование социальных систем. К социальным, по его мнению, принадлежат и так называемые этнические потребности, связанные с причислением себя к определенному этносу (там же: 48-49).

Классификация С. Б. Каверина строится на различении четырех основных видов деятельности (труд, общение, познание и рекреация), каждому из которых соответствует своя группа потребностей, начиная с биологического прототипа и далее в последовательности, отражающей более высокую ступень социализации. Так, трудовой деятельности соответствует базовая потребность в безопасности и самосохранении, а базовая потребность в эмоциональном контакте постепенно переходит в потребность в общении и затем - в нравственные потребности. Потребность в эмоциональном контакте у С. Б. Каверина по-иному называется потребностью включения в социум. Познавательной и рекреативной деятельности соответствуют такие базовые потребности, как ориентировочная потребность и потребность в двигательной активности. На высшем уровне социализации они, в свою очередь, соотносятся с потребностями в смысле жизни и в подготовленности к преодолению препятствий (Каверин, 1998: 34-38). 
Потребности, будучи связанными как с биологической, так и с социальной природой человека, играют важную роль в формировании его поведения. Анализ классификаций позволяет выделить базовые (основные) и производные потребности. К первым следует в первую очередь отнести потребность в самосохранении и аффилиативную потребность.

\section{АФФИАИАТИВНАЯ ПОТРЕБНОСТЬ И ЭТНИЧЕСКАЯ ИАЕНТИЧНОСТЬ}

С учетом рассмотренных классификаций важно выделить связь между этнической идентичностью и аффилиативной потребностью, на основе которой прослеживается взаимосвязь этнической идентичности с Аругими потребностями.

Во-первых, аффилиативная потребность, несмотря на свою генетическую связь с биологическими потребностями (Каверин, 1998: 37; Симонов, 1987: 50), является одной из основных специфических потребностей человека (Хотинец, 2002: 114; Фромм, 2006: 36; Обуховский, 1974: 54; Парыгин, 1974: 95; Аинтон, 2001: 73, 82, 84-85). Каким бы ни был генезис аффилиативной потребности, по своим функциям она связана с сохранением социума, поскольку биологические потребности первичны дишь с точки зрения времени возникновения, а социальные являются приоритетными в структурно-функциональном смысле (Асеев, 1974). И так как человек не может выжить без сотрудничества с другими (Фромм, 2006: 31, 33-36; Аинтон, 2001: 76; Апресян, 1995: $126-127,144,146)$, то аффилиативная потребность - необходимое условие реализации потребности в самосохранении.

Во-вторых, в выделенных выше классификациях подчеркивается взаимосвязь аффилиативной потребности с потребностями следования нормам, отражающим ценностный смысл включенности в социальную среду (Каверин, 1998: 37; Симонов, 1987: 49). Представляется, что аффилиативная потребность, потребность в самосохранении и потребность следования нормам тесно связаны между собой. Так, принято подчеркивать взаимозависимость существования нравственных норм и самосохранения коллектива (Токарев, 1972: 266, 272; Семенов, 1989: 187-188, 193-194, 200-201; Шимановский, 1976: 32, 34; Каверин, 1998: 37; Аинтон, 2001: 73, 82, 84-85). Они возникают только с появлением соответствующей потребности в регулировании (Шимановский, 1976: 31), которая, в свою очередь, обусловлена необходимостью обеспечить функционирование социума. Нравственные потребности отражают интересы коллектива (Аробницкий, 1974: 237, 239; Гусейнов, 1974: 51, 53, 55) и являются проявлением аффилиативной потребности.

Таким образом, через аффилиативную потребность можно проследить взаимосвязь этнической идентичности как со специфическими человеческими потребностями - потребностью в нормативном регулировании, так и с базовыми витальными потребностями в виде потребности в самосохранении. Взаимосвязь с этими фундаментальными потребностями лежит в основе устойчивости этнической идентичности.

\section{ЭТНИЧЕСКАЯ ИАЕНТИЧНОСТЬ КАК СПОСОБ РЕААИЗАЦИИ ПОТРЕБНОСТИ В САМОСОХРАНЕНИИ}

Этническая идентичность часто рассматривается в качестве приоритетной по отношению к другим видам идентичностей. Подобный приоритет отдается ей и в примордиализме, где она понимается как приобретаемая индивидом при рождении (Isaacs, 1975: 32-34), и в конструктивизме, где она связывается со статусом, вышестоя- 
щим по отношению к большинству других идентичностей и налагающим ограничения на все виды деятельности (Барт, 2006а: 20).

Коренное отличие этнической идентичности обусловлено также ее ориентацией в прошлое, что дает ощущение смысла существования (De Vos, Romanucci-Ross, 1975: 363-364). Ее специфические черты могут быть выявлены и при анализе существующих подходов к этничности, а именно: рассматривается ли этническая идентичность как сущностная ценность или же служит инструментальным целям. Так, одним из ключевых в субъективистском подходе является представление о рациональном выборе этнической идентичности (Обсуждение доклада ..., 1998: 46), который трактуется как средство достижения политических, экономических и прочих целей (Скворцов, 1996а: $10,112-114,124)$. Яркий пример рациональной смены этнической идентичности описан Ф. Бартом - о пуштунах, становящихся белуджами (Барт, 2006а: 27). По свидетельству автора, белуджи более успешны во внешних конфликтах. На границе с хазарейцами изменения пуштунской идентичности не происходит (там же: 152, 154). Смену идентичности на границе с белуджами Ф. Барт трактует как следствие «провальных результатов», которые предоставляет индивиду пуштунская идентичность в новых обстоятельствах (Барт, 2006a: 31; 2006b: 161).

Смена идентичности может рассматриваться в данном случае как механизм адаптации и выживания индивида или группы в условиях, когда старые нормы поведения перестают соответствовать новой социальной среде. Чтобы получить ценимые материальные или социальные блага и воспользоваться возможностями, предоставляемыми обществом, индивид вынужден избавляться от своих специфических этнических характеристик или скрывать их, поскольку его оценка представителями доминирующей этнической группы является негативной, и демонстрация собственной идентичности связана с понижением социального статуса (Эйдхейм, 2006: 56-57, 60-61). В исследовании X. Эйдхейма понижение социального статуса саамов западного Финнмарка означает осложнение их полноценного участия в экономической жизни общества как условия жизнеобеспечения. Их саамская идентичность связана с традиционными видами хозяйственной деятельности, с помощью которых саамы в данном регионе уже не имеют возможности в должной мере удовлетворять свои потребности в жизнеобеспечении. Аналогичным образом индивид в Аарфуре получает доступ к необходимым средствам производства, практикуя определенные модели поведения, связанные с этническими ярлыками (Барт, 2006а: 32).

В вопросе о сознательном изменении этнической идентичности представители конструктивистского подхода разделяют два момента, касающиеся социальной и личностной ориентации. Первый отражает особенности регулирования взаимодействия между людьми, осуществляемого посредством ценностей и норм. «Фор, - пишет Г. Холанд, - превращается в баггара в тот момент, когда становится номадом» (Холанд, 2006: 87). С этой точки зрения важны категоризация его как баггара другими и регулирование его поведения теми же правилами, что и баггара.

Относительно личностной ориентации признается, например, что личность форского крестьянина не изменяется сразу после того, как он становится номадом. $Ф$. Барту также приходилось слышать от отдельных групп белуджей, что они «на самом деле пуштуны». Поэтому он отмечает, что этническая идентичность оказывается здесь одновременно и вопросом происхождения, и нынешней идентичности (Барт, 2006а: 36), но этот личностный аспект остается в стороне (Холанд, 2006: 87). Принятие во внимание только социального момента означает, что рассматривается изменение 
лишь одного из компонентов этнической идентичности, который связан с адаптацией к социальным условиям и реализацией экономических потребностей, являющихся промежуточными на пути к удовлетворению базовых потребностей (Байльдинов, 2010: 68-69) - в частности, потребности в самосохранении.

Смена этнической идентичности в связи с вопросами личностной ориентации касается реализации определенных психологических потребностей. Пониманию этого вопроса служит рассмотрение этнической идентичности как символической конструкции, реализующейся с помощью психологических механизмов (Скворцов, 1996b: 45-46, 48). При таком понимании этничность может рассматриваться как когнитивная карта истории и современности, обеспечивающая связь поколений и основу интерпретации жизненного опыта (Коротеева, 1994: 46). Поскольку психика является отражением культурной среды, построенной на определенной нормативно-ценностной основе (Карлов, 2010: 33), то в этом смысле этническая идентичность связана с сохранением значимых ценностей, выражающих потребности в устойчивом способе существования (Хотинец, 2002: 114; Стефаненко, 1998: 90, 92; Степанов, Сусоколов, 1990: 52-53).

Подобную функцию выделяет Э. Фромм и для аффилиативной потребности в целом (Фромм, 2006: 36), а Э. Эриксон - для идентичности (Эриксон, 2006: 40, 49). Специфика же аффилиации с этнической общностью обусловлена приоритетным положением этнической идентичности среди других идентичностей, поэтому соотнесение себя с этнической общностью является необходимым условием реализации данной потребности.

Постепенная смена этнической идентичности в ходе социализации охватывает изменение целостной структуры этнической идентичности. Оно также связано с потребностью в самосохранении. В качестве примера можно привести наблюдения Р. Парка о втором поколении китайских и японских эмигрантов в Америке (Парк, 2001: 108-109). Аля них социализация проходила в ситуации, когда этническая принадлежность их родителей затрудняла реализацию потребности в самосохранении. Подобные процессы социализации описываются и представителями конструктивизма (Эйдхейм, 2006: 54, 58-59). Рациональность изменения этнической идентичности представляет собой здесь долговременную жизненную стратегию, нацеленную на выживание в изменяющихся социальных условиях.

Однако реализация потребности в самосохранении при изменении социальных условий возможна не только с помощью изменения этнической идентичности, но и посредством ее сохранения, как это происходило с саамами внутренней части Финнмарка и хауса в Ибадане. Такой путь реализации данной потребности возможен, если сохраняется экономическая ниша, обеспечивающая полноценное участие в жизни общества (Эйдхейм, 2006: 51-52; Cohen, 1969: 191-192).

На основе примеров конструктивистских и инструменталистских подходов прослеживается связь этнической идентичности с социально-экономической сферой, являющейся основой обеспечения потребности в самосохранении. Возникает вопрос: почему этническая идентичность так тесно связана с потребностью в самосохранении? Представляется, что объяснение этой взаимосвязи может дать теория этноса.

Свойственное теории этноса исследование этнических явлений в диахронном разрезе позволяет сделать вывод, что изначально этническая общность обеспечивала полный цикл жизнедеятельности индивида и удовлетворение всех необходимых по- 
требностей (Мархинин, 1989: 50). Традиционному обществу была свойственна нерасчлененность всех сторон жизни человека (Карлов, 2010: 44-45). Сопоставление подобной нерасчлененности сфер деятельности с классификацией С. Б. Каверина позволяет говорить о действительно существовавшей в тот период возможности реализации всего комплекса наличных потребностей индивида в рамках этнической общности.

Переход к формам жизнеобеспечения индустриального общества привел к тому, что связанные с воспроизводством культуры институты стали выполнять функции, которые ранее выполнял весь жизнеобеспечивающий комплекс (там же: $33,35,38$ ). В связи с этим реализация потребностей, осуществляемая этнической общностью, расщепляется и переходит на символический и психологический уровень. Именно поэтому возникает такое явление, как смена этнической идентичности в форме изменения набора ценностей и норм, которым следует в своем поведении индивид. Расщепление реализации потребностей также дает возможность разделять исследования социального и личностного моментов этнической идентичности. В качестве проявления этой тенденции должен рассматриваться рост опосредованности процесса их реализации. В частности, потребность в самосохранении начинает реализовываться через использование этнической идентичности для удовлетворения экономических потребностей. Потребность в самосохранении реализуется также в форме обеспечения психологического комфорта существования индивида, и особую значимость приобретает ценностный компонент этнической идентичности.

\section{ВЗАИМОЗАВИСИМОСТЬ ЭТНИЧЕСКОЙ ИАЕНТИЧНОСТИ \\ И ПОТРЕБНОСТИ В НОРМАТИВНОМ РЕГУАИРОВАНИИ}

Ценностно-нормативному компоненту придается большое значение в рамках всех подходов к исследованию этничности и этнической идентичности (Першиц, 1982: 8-11; Аробижева, 1994a: 72; 1994b: 11; De Vos, Romanucci-Ross, 1975: 366-367). Особенно значимым изучение ценностных ориентаций является для конструктивистского подхода. Этническая идентичность ассоциируется здесь с определенным набором стандартов ценностей (Барт, 2006а: 31). Принадлежность к этнической категории предполагает общность таких стандартов (Барт, 2006а: 16-18).

Поскольку существование любого общества предполагает наличие основных ценностей, принимаемых членами этого общества (Ивин, 2005: 328-329), первоначальное обеспечение этнической общностью всего цикла жизнедеятельности индивида было бы невозможно без социальных норм, нарушение которых угрожает выживанию группы (De Vos, Romanucci-Ross, 1975: 366, 367). Именно в силу своей специфики этническая идентичность связана с потребностью в следовании социальным нормам.

Изначально появление и функционирование социальных норм связано со всей совокупностью духовной и материальной сфер жизни общества, которые существовали в неразрывном единстве. Постепенное усложнение общества подразумевает разделение материальной и духовной сфер. В связи с этим ценности и нормы перестают быть обусловленными непосредственными условиями жизнедеятельности, перестают служить первоначально заложенным в них целям, связанным с непосредственным удовлетворением основных человеческих потребностей, и начинают использоваться как средство. Подобное использование ценностных ориентаций в инструментальных целях рассматривается представителями конструктивистского подхода. В частности, характерным здесь является пример перехода оседлых фор в группу кочевых баггара. 
Этот переход здесь не вполне обусловлен необходимостью обеспечения выживания индивида и реализации его потребности в самосохранении, поскольку подобную возможность дает и идентичность фор. И переход в баггара связан для фор лишь с необходимостью обеспечить сохранность накоплений, которые осуществляются в форме скота (Холанд, 2006: 79).

\section{ЗАКАЮЧЕНИЕ}

Существование этнической идентичности связано с базовыми потребностями человека, имеющими как биологическую, так и социальную природу. Среди них определяющими являются потребности в самосохранении, принадлежности к группе, нормативном регулировании и обеспечении психологического комфорта существования.

Связь этнической идентичности с этими потребностями может быть прослежена на основании соединения диахронного подхода и существующих интерпретаций этничности. Теория этноса свидетельствует о связи этнических явлений со всем комплексом жизнеобеспечения, и в частности с социально-экономическими факторами, обеспечивающими реализацию всех жизненно важных потребностей, и прежде всего потребности в самосохранении. Инструменталистский и конструктивистский подходы позволяют рассмотреть взаимосвязь этнической идентичности с потребностью в самосохранении в аналогичном социально-экономическом контексте, но уже в исторически отличных общественных условиях, учитывающих усложнение социальной структуры и расщепление целостного жизнеобеспечивающего механизма.

Все подходы в целом позволяют выявить значимость ценностного компонента в структуре этнической идентичности, но осознание его важности дает именно использование диахронного подхода, позволяющего выявлять взаимосвязь между ценностями и нормами и функционированием этнической общности на начальном этапе ее существования, и дает возможность проследить дальнейшую эволюцию механизма функционирования норм и ценностей. Так, в ходе усложнения общественного развития и разделения материальной и духовной сфер жизни они начинают осознанно использоваться как инструмент для достижения определенных целей, которые лишь опосредованно могут быть связанными с реализацией потребности в самосохранении либо не связанными с ней вообще.

Значение разделения духовной и материальной сфер жизни общества также находит свое отражение в символическом и психологическом подходе к этнической идентичности. Последний формируется под влиянием обособления психологических потребностей индивида из целостного комплекса жизнеобеспечения. Таким образом, возникает необходимость выделить взаимосвязь этнической идентичности с потребностью индивида в обеспечении психологически стабильного его существования.

Как представляется, одним из перспективных направлений исследования проблем этнической идентичности может выступать изучение ее связи с традиционной этнической культурой. Надо при этом иметь в виду, что сама данная культура является, с одной стороны, достаточно устойчивой в своих основах, с другой стороны, динамичной системой, постоянно адаптирующейся к изменяющимся социальным условиям. Поэтому традиция в настоящее время часто существует не в виде аутентичной традиции, а как неотрадиция, неотрадиционализм. Поэтому реальная научная проблема может быть конкретизирована как проблема взаимосвязи нетрадиционализма и этнической идентичности. Она может быть предметом специального рассмотрения. 
СПИСОК АИТЕРАТУРЫ

Апресян, Р. Г. (1995) Идея морали и базовые нормативно-этические программы. М. : Изд-во Ин-та философии РАН. 353 с.

Асеев, В. Г. (1974) Об истоках человеческой мотивации // Проблемы формирования социогенных потребностей : материалы I Всесоюз. конф. (4-6 ноября 1974 г., Тбилиси) / отв. ред. Ш. Н. Чхартишвили, Н. И. Сарджвеладзе. Тбилиси : Ин-т психологии. 307 с. С. 8-11.

Байльдинов, Е. (2010) Потребности индивида и развитие общества // Общество и экономика. № 2. С. 64-72.

Барт, Ф. (2006а) Введение // Этнические группы и социальные границы. Социальная организация культурных различий / отв. ред. Ф. Барт. М. : Новое издательство. 200 с. С. 9-49.

Барт, Ф. (2006b) Пуштунская идентичность и поддержание ее сохранности // Этнические группы и социальные границы. Социальная организация культурных различий / отв. ред. Ф. Барт. М. : Новое издательство. 200 с. С. 142-165.

Гусейнов, А. А. (1974) Социальная природа нравственности. М. : Изд-во Моск. ун-та. 157 с.

Аробижева, А. М. (1994а) Интеллигенция и национализм. Опыт постсоветского пространства // Этничность и власть в полиэтничных государствах / отв. ред. В. А. Тишков. М. : Наука. 320 с. C. 71-85.

Аробижева, А. М. (1994b) Ценности и символы в контексте новых концепций этничности // Ценности и символы национального самосознания в условиях изменяющегося общества / отв. ред. А. М. Аробижева, Т. С. Гузенкова. М. : Ин-т этнологии и антропологии РАН. 236 с. С. 8-25.

Аробницкий, О. Г. (1974) Понятие морали. Историко-критический очерк. М. : Наука. 388 с.

Ивин, А. А. (2005) Современная философия науки. М. : Высшая школа. 592 с.

Каверин, С. Б. (1998) Мотивация труда. М. : Ин-т психологии РАН. 224 с.

Каган, М. С., Маргулис, А. В., Хмелев, А. М. (1976) Постановка проблемы потребностей в современной науке // Проблема потребностей в этике и әстетике / отв. ред. М. С. Каган, В. Г. Иванов. $\Lambda$. : Изд-во Аенингр. ун-та. Вып. 3. 175 с. С. 5-15.

Карлов, В. В. (2010) Народы северо-восточной Евразии в ХІХ и XX веках. М. : КАУ. 476 с.

Коротеева, В. В. (1994) Этнические символы и символическая природа этничности, концепции Аж. Армстронга, Э. Смита и Э. Хобсбаума // Ценности и символы национального самосознания в условиях изменяющегося общества / отв. ред. А. М. Аробижева, Т. С. Гузенкова. М. : Ин-т этнологии и антропологии РАН. 236 с. С. 37-55.

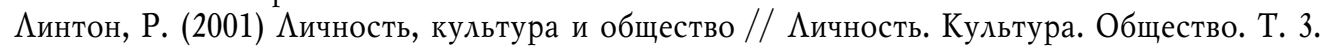
Вып. 1. С. 68-87.

Мархинин, В. В. (1989) Аиалектика социального и биологического в процессе становления этноса (философско-социологический аспект). Томск : Изд-во Томск. ун-та. 145 с.

Мертон, Р. (1994) Явные и латентные функции // Американская социологическая мысль / сост. Е. И. Кравченко ; под ред. В. И. Аобренькова. М. : Изд-во МГУ. 496 с. С. 379-448.

Обсуждение доклада В. А. Тишкова «О феномене этничности» (1998) / В. А. Тишков, Т. С. Гузенкова, А. А. Коростелев, С. Н. Абашин, Е. И. Филиппова, А. Н. Ямсков, А. М. Аробижева, Г. У. Солдатова, В. Р. Филиппов // Этнографическое обозрение. № 1. С. 31-50.

Обуховский, К. (1974) Потребности и их классификация // Проблемы формирования социогенных потребностей : материалы I Всесоюз. конф. (4-6 ноября 1974 г., Тбилиси) / отв. ред. Ш. Н. Чхартишвили, Н. И. Сарджвеладзе. Тбилиси : Ин-т психологии. 307 с. С. 53-56.

Парк, Р. Э. (2001) По ту сторону наших масок // Иичность. Культура. Общество. Т. 3. Вып. 1. 308 c. C. $101-114$.

Парыгин, Б. А. (1974) Научно-техническая революция и динамика социальных потребностей // Проблемы формирования социогенных потребностей : материалы I Всесоюз. конф. (4-6 ноября 1974 г., Тбилиси) / отв. ред. Ш. Н. Чхартишвили, Н. И. Сарджвеладзе. Тбилиси : Ин-т психологии. 307 с. С. $95-98$.

Першиц, А. И. (1982) Проблема аксиологических сопоставлений в культуре // Советская этнография. № 3. С. 3-12.

Семенов, Ю. И. (1989) На заре человеческой истории. М. : Мысль. 319 с. 
Симонов, П. В. (1987) Мотивированный мозг. Высшая нервная деятельность и естественнонаучные основы общей психологии. М. : Наука. 270 с.

Скворцов, Н. Г. (1996а) Проблемы этничности в социальной антропологии. СПб. : 1996. 184 с.

Скворцов, Н. Г. (1996b) Этничность в современном обществе: подходы и проблемы // Возрождение культуры России: диалог культур и межнациональные отношения. Вып. 4 / сост. С. М. Климов ; редкол.: В. Т. Пуляев, К. Н. Хабибуллин, Н. Г. Скворцов. СПб. : Знание. 127 с. C. $45-54$.

Степанов, В. В., Сусоколов, А. А. (1990) Этнос и его среда // Человек. № 6. С. 52-55.

Стефаненко Т. Г. (1998) Этническая идентичность и некоторые проблемы ее изучения // Этнос. Идентичность. Образование. Труды по социологии образования / отв. ред. В. С. Собкина. T. 4. Вып. 6. М. : Центр социологии образования РАО. 268 с. С. 85-105.

Токарев, С. А. (1972) Проблемы общественного сознания доклассовой эпохи // Охотники. Собиратели. Рыболовы. Проблемы социально-экономических отношений в доземледельческом обществе. М. : Наука. 381 с. С. 236-379.

Фромм, Э. (2006) Бегство от свободы : пер. с англ. М. : АСТ. 571 с.

Холанд, Г. (2006) Экономические факторы в этнических процессах // Этнические группы и социальные границы. Социальная организация культурных различий / отв. ред. Ф. Барт. М. : Новое издательство. 200 с. С. 73-92.

Хотинец, В. Ю. (2002) Этническая идентичность и толерантность. Екатеринбург : Изд-во Уральск. ун-та. 121 с.

Шимановский, А. С. (1976) Генезис нравственных потребностей // Проблема потребностей в этике и эстетике / отв. ред. М. С. Каган, В. Г. Иванов. А. : Изд-во Иенингр. ун-та. Вып. 3.175 с. C. 31-37.

Эйдхейм, Х. (2006) Когда этническая идентичность становится социальным стигматом? // Этнические группы и социальные границы. Социальная организация культурных различий / отв. ред. Ф. Барт. М. : Новое издательство. 200 с. С. 50-73.

Эриксон, Э. (2006) Идентичность: юность и кризис : пер. с англ. М. : Флинта : МПСИ : Прогресс. 352 c.

Cohen A. (1969) Custom and Politics in Urban Africa. A Study of Hausa Migrants in Yoruba Towns. Berkley and Los Angeles, University of California Press. 252 p.

De Vos, G., Romanucci-Ross, L. (1975) Ethnicity: Vessel of Meaning and Emblem of Contrast // Ethnic Identity. Cultural Continuities and Change. Ed. by G. De Vos, L. Romanucci-Ross. California, Mayfield Publishing Company, Palo Alto. 395 p. P. 363-389.

Isaacs H. R. (1975) Basic Group Identity: The Idols of the Tribe. Ethnicity: Theory and Experience. ed. by N. Glazer and D. P. Moynihan. Cambridge, Harvard university press. 531 p. P. 29-52.

Аата поступления: 15.02.2016 2.

\section{ETHNIC IDENTITY IN THE CONTEXT OF THEORY OF NEEDS \\ O. V. DOLZHenkova, Yu. V. POPKOV \\ (INSTITUTE of Philosophy AND LAW, Siberian BRANCH, \\ RUSSIAN ACADEMY OF SCIENCES, NOVOSIBIRSK)}

The article offers a look at ethnic identity as a phenomenon that arises due to persistent needs. Our aim was to identify the specific needs which facilitate the rise of ethnic identity, on the basis of a wide variety of sources. The study has shown that ethnic identity stems from affiliative need, and as such it can be traced both to specific human needs (e.g., the need for regulation) and to vital biological needs, such as self-preservation.

Given this character of ethnic identity, we can link it to the socioeconomic sphere as the provider of self-preservation.

In particular, a change in ethnic identity can be viewed as a survival strategy: it enables full-scale participation in economic life when the old norms of behavior no longer match the requirements of the modified social environment. This strategy can also work via preserving one's ethnic identity if 
there is an economic niche which helps those identifying themselves with a certain ethnicity to fully adapt to the current social conditions. The link between ethnic identity and the need for self-preservation through economic needs is so enduring due to the fact that originally an ethnic community covered the full cycle of their members' lives and satisfied all of their urgent needs. In its turn, this could be explained by the syncretism of human existence in a traditional society.

The separation of social and personal orientations in the study of ethnic identity reflects the dissociation of this holistic existence. Thus, a change in ethnic identity viewed in its personal context indicates the split-off of a need for individual psychological stability.

Another consequence of the dissociation of the holistic existence lies in the increasingly indirect provision of basic needs. The need for self-preservation starts being satisfied via the instrumental use of ethnic identity to provide for the economic needs. Studying the norms and values as a component of ethnic identity thus becomes especially important. Ethnic identity retains the link with normative regulation, since originally it was the ethnic community which provided for individuals' needs throughout the full cycle of their activity. However, after the dissociation of the material and spiritual values are no longer directly connected to the need for self-preservation and can now also be instrumentalized.

Keywords: ethnic identity; ethnicity; needs; self-preservation as a need; values

\section{REFERENCES}

Apresian, R. G. (1995) Ideia morali i bazovye normativno-eticheskie programmy [The idea of morality and basic programs in normative ethics]. Moscow, Institute of Philosophy Press, Russian Academy of Sciences. 353 p. (In Russ.).

Aseev, V. G. (1974) Ob istokakh chelovecheskoi motivatsii [On the origins of motivation in humans]. In: Problemy formirovaniia sotsiogennykb potrebnostei : materialy I Vsesoiuz. konf. (4-6 noiabria 1974 g., Tbilisi) [The issues of building sociogenic needs. Proceedings of 1st All-USSR conference, November 4-6, 1974, Tbilisi]. Ed. by Sh. N. Chkhartishvili and N. I. Sardzhveladze. Tbilisi, Institute of Psychology Press. 307 p. Pp. 8-11. (In Russ.).

Bail'dinov, E. (2010) Potrebnosti individa i razvitie obshchestva [Individual needs and the development of society]. Obshchestvo i ekonomika, no. 2, pp. 64-72. (In Russ.).

Barth, F. (2006a) Vvedenie [Introduction]. In: Barth, F. (ed.) Etnicheskie gruppy $i$ sotsial'nye granitsy. Sotsial'naia organizatsiia kul'turnykb razlichii [Ethnic Groups and Boundaries: The Social Organization of Culture Difference]. Moscow, Novoe izdatel'stvo. 200 p. Pp. 9-49. (In Russ.).

Barth, F. (2006b) Pushtunskaia identichnost' i podderzhanie ee sokhrannosti [Pathan identity and its maintenance]. In: Barth, F. (ed.) Etnicheskie gruppy $i$ sotsial'nye granitsy. Sotsial'naia organizatsiia kul'turnykh razlichii [Ethnic Groups and Boundaries: The Social Organization of Culture Difference]. Moscow, Novoe izdatel'stvo. 200 p. Pp. 142-165. (In Russ.).

Guseinov, A. A. (1974) Sotsial' naia priroda nravstvennosti [The social nature of morality]. Moscow, Moscow University Press. 157 p. (In Russ.).

Drobizheva, L. M. (1994a) Intelligentsiia i natsionalizm. Opyt postsovetskogo prostranstva [Intelligentsia and nationalism. The post-Soviet experience]. In: Etnichnost' $i$ vlast' v polietnichnykb gosudarstvakb [Ethnicity and power in polyethnic states]. Ed. by V. A. Tishkov. Moscow, Nauka Publ. 320 p. Pp. 71-85. (In Russ.).

Drobizheva, L. M. (1994b) Tsennosti i simvoly v kontekste novykh kontseptsii etnichnosti [Values and symbols in the context of new concepts of ethnicity]. In: Tsennosti i simvoly natsional' nogo samosoznaniia $v$ usloviiakb izmeniaiushchegosia obshchestva [Values and symbols of ethnic self-consciousness in transforming society]. Ed. by L. M. Drobizheva and T. S. Guzenkova. Moscow, Institute of Ethnology and Anthropology, Russian Academy of Sciences. 236 p. Pp. 8-25. (In Russ.).

Drobnitskii, O. G. (1974) Poniatie morali. Istoriko-kriticheskii ocherk [The idea of morality. A historical and critical essay]. Moscow, Nauka Publ. 388 p. (In Russ.).

Ivin, A. A. (2005) Sovremennaia filosofiia nauki [Contemporary philosophy of science]. Moscow, Vysshaia shkola Publ. 592 p. (In Russ.). 
Kaverin, S. B. (1998) Motivatsiia truda [Motivation for work]. Moscow, Institute of Psychology, Russian Academy of Science. 224 p. (In Russ.).

Kagan, M. S., Margulis, A. V. and Khmelev, A. M. (1976) Postanovka problemy potrebnostei v sovremennoi nauke [The problem of needs in contemporary research]. In: Problema potrebnostei v etike $i$ estetike [The problem of needs in ethics and aesthetics]. Ed. by M. S. Kagan and V. G. Ivanov. Leningrad, Leningrad University Press. Iss. 3.175 p. Pp. 5-15. (In Russ.).

Karlov, V. V. (2010) Narody severo-vostochnoi Evrazii v XIX $i$ XX vekakb [Peoples of northeastern Eurasia in 19th and 20th centuries]. Moscow, KDU Publ. 476 p. (In Russ.).

Koroteeva, V. V. (1994) Etnicheskie simvoly i simvolicheskaia priroda etnichnosti, kontseptsii Dzh. Armstronga, E. Smita i E. Khobsbauma [Ethnic symbolism and the symbolic nature of ethnicity: the theories of J. Armstrong, A. Smith and E. Hobsbawm]. In: Tsennosti $i$ simvoly natsional' nogo samosoznaniia $v$ usloviiakb izmeniaiushchegosia obshchestva [Values and symbols of ethnic self-consciousness in transforming society]. Ed. by L. M. Drobizheva and T. S. Guzenkova. Moscow, Institute of Ethnology and Anthropology, Russian Academy of Sciences. 236 p. Pp. 37-55. (In Russ.).

Linton, R. (2001) Lichnost', kul'tura i obshchestvo [Culture, society and the individual]. Lichnost'. Kul'tura. Obshchestvo, vol. 3, iss. 1, pp. 68-87. (In Russ.).

Markhinin, V. V. (1989) Dialektika sotsial' nogo i biologicheskogo v protsesse stanovleniia etnosa (filosofsko-sotsiologicheskii aspekt) [The dialectics of the social and biological in ethnogenesis]. Tomsk, Tomsk University Press. 145 p. (In Russ.).

Merton, R. (1994) Iavnye i latentnye funktsii [Manifest and latent functions]. In: Amerikanskaia sotsiologicheskaia mysl' [American sociological thought]. Ed. by V. I. Dobren'kov. Moscow, Moscow State University Press. 496 p. Pp. 379-448. (In Russ.).

Obsuzbdenie doklada V. A. Tishkova "O fenomene etnichnosti" (1998) [The discussion of V. A. Tishkov's "On the phenomenon of ethnicity"]/ V. A. Tishkov, T. S. Guzenkova, A. D. Korostelev, S. N. Abashin, E. I. Filippova, A. N. Iamskov, L. M. Drobizheva, G. U. Soldatova and V. R. Filippov. Etnograficheskoe obozrenie, no.1, pp. 31-50. (In Russ.).

Obukhovskii, K. (1974) Potrebnosti i ikh klassifikatsiia [Needs and their classification]. In: Problemy formirovaniia sotsiogennykb potrebnostei : materialy I Vsesoiuz. konf. (4-6 noiabria 1974 g., Tbilisi) [The issues of building sociogenic needs. Proceedings of 1st All-USSR conference, November 4-6, 1974, Tbilisi]. Ed. by Sh. N. Chkhartishvili and N. I. Sardzhveladze. Tbilisi, Institute of Psychology Press. 307 p. Pp. 53-56. (In Russ.).

Park, R. E. (2001) Po tu storonu nashikh masok [Behind our masks]. Lichnost'. Kul'tura. Obshchestvo, vol. 3, iss. 1, pp. 101-114. (In Russ.).

Parygin, B. D. (1974) Nauchno-tekhnicheskaia revoliutsiia i dinamika sotsial'nykh potrebnostei [The revolution in science and technology and the dynamics of social needs]. In: Problemy formirovaniia sotsiogennykb potrebnostei : materialy I Vsesoiuz. konf. (4-6 noiabria 1974 g., Tbilisi) [The issues of building sociogenic needs. Proceedings of 1st All-USSR conference, November 4-6, 1974, Tbilisi]. Ed. by Sh. N. Chkhartishvili and N. I. Sardzhveladze. Tbilisi, Institute of Psychology Press. 307 p. Pp. 95-98. (In Russ.).

Pershits, A. I. (1982) Problema aksiologicheskikh sopostavlenii v kul'ture [The problem of axiological comparison in culture]. Sovetskaia etnografiia, no. 3, pp. 3-12. (In Russ.).

Semenov, Iu. I. (1989) Na zare chelovecheskoi istorii [At the dawn of human history]. Moscow, Mysl' Publ. 319 p. (In Russ.).

Simonov, P. V. (1987) Motivirovannyi mozg. Vysshaia nervnaia deiatel'nost' $i$ estestvenno-nauchnye osnovy obshchei psikbologii [The motivated mind. Higher nervous activity and the rise of general psychology from natural science]. Moscow, Nauka Publ. 270 p. (In Russ.).

Skvortsov, N. G. (1996a) Problemy etnichnosti v sotsial' noi antropologii [The problems of ethnicity in social anthropology]. St. Petersburg, 1996. 184 p. (In Russ.).

Skvortsov, N. G. (1996b) Etnichnost' v sovremennom obshchestve: podkhody i problemy [Ethnicity in contemporary society: Approaches and problems]. In: Vozrozbdenie kul'tury Rossii: dialog kul'tur $i$ mezhnatsional' nye otnosheniia [The revival of Russia's culture: Cultural dialogue and inte- 
rethnic relations]. Iss. 4. Ed. by: V. T. Puliaev, K. N. Khabibullin and N. G. Skvortsov. St. Petersburg, Znanie Publ. 127 p. Pp. 45-54. (In Russ.).

Stepanov, V. V. and Susokolov, A. A. (1990) Etnos i ego sreda [Ethnicity and its environment]. Chelovek, no. 6, pp. 52-55. (In Russ.).

Stefanenko T. G. (1998) Etnicheskaia identichnost' i nekotorye problemy ee izucheniia [Ethnic identity and certain issues of studying it]. In: Etnos. Identichnost'. Obrazovanie. Trudy po sotsiologii obrazovaniia [Ethnicity. Identity. Education]. Ed. by V. S. Sobkina. Vol. 4. Iss. 6. Moscow, Center for Sociology of Education, Russian Academy of Education. 268 p. Pp. 85-105. (In Russ.).

Tokarev, S. A. (1972) Problemy obshchestvennogo soznaniia doklassovoi epokhi [Problems of social consciousness in the pre-class period]. In: Okbotniki. Sobirateli. Rybolovy. Problemy sotsial'no-ekonomicheskikb otnoshenii $v$ dozemledel'cheskom obshchestve [Hunters. Gatherers. Fishermen. Problems of socioeconomic relations in pre-agrarian society]. Moscow, Nauka Publ. 381 p. Pp. 236-379. (In Russ.).

Fromm, E. (2006) Begstvo ot svobody [Escape from freedom]. Moscow, AST Publ. 571 p. (In Russ.).

Haaland, G. (2006) Ekonomicheskie faktory v etnicheskikh protsessakh [Economic determinants in ethnic processes]. In: Barth, F. (ed.) Etnicheskie gruppy i sotsial'nye granitsy. Sotsial' naia organizatsiia kul'turnykh razlichii [Ethnic Groups and Boundaries: The Social Organization of Culture Difference]. Moscow, Novoe izdatel'stvo. 200 p. Pp. 73-92. (In Russ.).

Khotinets, V. Iu. (2002) Etnicheskaia identichnost' i tolerantnost' [Ethnic identity and tolerance]. Ekaterinburg, Ural University Press. 121 p. (In Russ.).

Shimanovskii, D. S. (1976) Genezis nravstvennykh potrebnostei [The genesis of moral needs]. In: Problema potrebnostei $v$ etike $i$ estetike [The problem of needs in ethics and aesthetics]. Ed. by M. S. Kagan and V. G. Ivanov. Leningrad, Leningrad University Press. Iss. 3. 175 p. Pp. 31-37. (In Russ.).

Eidheim, H. (2006) Kogda etnicheskaia identichnost' stanovitsia sotsial'nym stigmatom? [When ethnic identity is a social stigma]. In: Barth, F. (ed.) Etnicheskie gruppy $i$ sotsial'nye granitsy. Sotsial' naia organizatsiia kul' turnykh razlichii [Ethnic Groups and Boundaries: The Social Organization of Culture Difference]. Moscow, Novoe izdatel'stvo. 200 p. Pp. 50-73. (In Russ.).

Erikson, E. H. (2006) Identicbnost' : iunost' $i$ krizis [Identity: Youth and crisis]. Moscow, Flinta : MPSI : Progress Publ. 352 p. (In Russ.).

Cohen, A. (1969) Custom and Politics in Urban Africa. A Study of Hausa Migrants in Yoruba Towns. Berkley and Los Angeles, University of California Press. 252 p.

De Vos, G., Romanucci-Ross, L. (1975) Ethnicity: Vessel of Meaning and Emblem of Contrast. Ethnic Identity. Cultural Continuities and Change. Ed. By G. De Vos and L. Romanucci-Ross. California, Mayfield Publishing Company, Palo Alto. 395 p. Pp. 363-389.

Isaacs, H. R. (1975) Basic Group Identity: The Idols of the Tribe. Ethnicity: Theory and Experience. Ed. by N. Glazer and D. P. Moynihan. Cambridge, Harvard university press. 531 p. Pp. 29-52.

Submission date: 15.02.2016.

Аолженкова Ольга Викторовна - аспирант сектора этносоциальных исследований Института философии и права Сибирского отделения Российской академии наук. Адрес: 630090, Россия, г. Новосибирск, ул. Николаева, д. 8. Тел.: +7 (383) 330-22-40. Эл. адрес: corpusdva@yandex.ru. Научный руководитель - А-р филос. наук, проф. Ю. В. Попков.

Попков Юрий Владимирович - доктор философских наук, профессор, заместитель директора по научной работе и заведующий сектором этносоциальных исследований Института философии и права Сибирского отделения Российской академии наук. Адрес: 630090, Россия, г. Новосибирск, ул. Николаева, д. 8. Тел.: +7 (383) 330-22-40. Эл. адрес: yuripopkov54@mail.ru

Dolzhenkova Olga Viktorovna, Postgraduate Student, Sector of Ethnosocial Studies, Institute of Philosophy and Law, Siberian Branch, Russian Academy of Sciences. Postal address: 8 Nikolaev St., 
Novosibirsk, Russian Federation 630090. Tel.: +7(495) 974-29-47. E-mail: corpusdva@yandex.ru Research advisor - Doctor of Philosophy, Professor Yu.V. Popkov.

Popkov Yuri Vladimirovich, Doctor of Philosophy, Professor, Deputy Director for Research, Head of Sector of Ethno-Social Studies, Institute of Philosophy and Law, Siberian Branch, Russian Academy of Sciences. Postal address: 8 Nikolaev St., Novosibirsk, Russian Federation 630090. Tel.: +7 (383) 330-22-40. E-mail: yuripopkov54@mail.ru 